\title{
Long-Term Energy and Momentum Flux Fluctuations of the Solar Wind at $1 \mathrm{AU}$
}

\author{
G. ZASTENKER and N. BORODKOVA
}

Space Research Institute, Academy of Sciences, Moscow, USSR

(Received July 30, 1990; Revised November 22, 1990)

\begin{abstract}
The paper is concerned with the variations of solar wind kinetic energy, ion thermal energy, ion flux and momentum as observed by near-Earth spacecraft over time scales from seconds to several days. The mean values of these fluxes and characteristics of their variability are discussed. The average variations of kinetic energy and momentum flux are about $10 \%$ of the mean values over a one-hour interval. Consideration is given to the differences in the energy and momentum flux for low-velocity and high-velocity solar wind streams. The discussion is extended with an analysis of very intense disturbances of energy and momentum due to the arrival of an interplanetary shock wave at Earth.
\end{abstract}

\section{Introduction}

It had been readily apparent as early as the late fifties that the solar wind was one of the main agents transferring perturbations from Sun to Earth (BIERMANN, 1951; PARKER, 1958). The transport of energy and momentum should be the most important characteristic of the solar wind's effect on the geomagnetosphere. These parameters can be determined from direct measurements of plasma velocity, temperature and density in the interplanetary medium (HUNDHAUSEN, 1972; FELDMAN et al., 1977; SCHWENN, 1983). Nevertheless, many aspects of the variability of solar wind energy and momentum have not been adequately studied up to the present time. This variability should not be limited to a description of the time characteristics of the measured values, but should also be examined to assess its capability to produce variations of many geomagnetospheric parameters.

Our paper is based mainly on the analysis of synoptic measurements of solar wind parameters onboard the Prognoz-7, 8, 10 satellites (VAISBERG et al., 1979). The methodology and instruments have been described elsewhere (VAISBERG et al., 1979; ZASTENKER et al., 1982). It should be noted that the nominal time resolution for proton velocity $(V)$, temperature $(T)$ and density $(n)$ measurements was usually 4-8 $\min$ (for ion flux $(N=n V): 10 \mathrm{~s})$. These measurements were recorded in 1978-79, 1981 and 1985. Our data base includes more than 35000 sets of parameters and about 25 times more values of ion flux at the above-mentioned sample rates. For selected short periods, however, measurements of ion flux were recorded at rates up to 50 times per second and the other parameters were measured once per second.

Analysis of these Prognoz data allows us to compare the behaviour of the flow parameters of the solar wind $\alpha$-particles and protons (AVANOV et al., 1987; YERMOLAEV et al., 1989) and variations of the solar wind heavy ion fluxes (AVANOV et al., 1987; ZASTENKER et al., 1989). Estimates were made of the energy and dynamic pressure 
associated with strong interplanetary shock waves (ZASTENKER and BORODKOVA, 1984; ZASTENKER et al., 1989). In this paper we describe the mean values and the variability of the solar wind energy and momentum fluxes.

\section{Mean Values of Energy and Momentum Flux}

Histograms of the distributions of the fluxes of kinetic energy $\left(F(E k)=n m V^{3} / 2\right.$, $m$-proton mass), ion thermal energy $(F(E t)=n k T V)$, particle $(N)$ and momentum (or dynamic pressure $P d=n m V^{2}$ ) are given in Fig. 1. Each of these panels shows the distribution for the entire data set (panels "b", "d", "f", "h"), as well as those for lowvelocity solar wind streams ( $V<350 \mathrm{~km} / \mathrm{s}$; thin lines on panels "a", "c", "e", "g") and for high-velocity streams $(V>550 \mathrm{~km} / \mathrm{s}$; lines with asterisks on panels "a", "c", "e", "g"). The total number of measurements is $\sim 11000$ for all data, $\sim 1500$ for slow wind and $\sim 1000$ for fast wind.

The average and standard deviations values of these parameters are given in Table 1 . The same table gives, for comparison, the mean values and standard deviations of momentum and energy fluxes from Vela and IMP (1971-74) and Helios 1/2 (1975-76) data (note that bounds of "slow" and "fast" winds are similar but not the same).

Of particular interest is the kinetic energy flux, responsible to a large extent for the solar wind's effect on processes in the Earth's vicinity. According to our data, the mean value of this quantity is $0.63 \mathrm{erg} / \mathrm{cm}^{2} \mathrm{~s}$, in good agreement with the Vela and IMP data $\left(0.70 \mathrm{erg} / \mathrm{cm}^{2} \mathrm{~s}\right)$ (FELDMAN et al., 1977), and with the Helios $1 / 2$ measurements $(0.52$ $\mathrm{erg} / \mathrm{cm}^{2} \mathrm{~s}$ ) (SCHWENN, 1983). The fact that these estimates coincide over such a long period (1971-1979) indicates that the mean kinetic energy flux has a relatively weak dependence on the solar activity cycle. The same result was found for mean total energy flux on Helios data (1974-82) (SCHWENN, 1983). Knowing the mean kinetic energy flux, it is easy to estimate the total energy input of the solar wind (assuming that contributions from the thermal and magnetic components do not exceed $10 \%$ of the total) impacting the Earth's magnetospheric cross section. Assuming a mean flank distance to the magnetopause of $15 \mathrm{R}_{\mathrm{E}}$, one obtains $\left\langle F_{t}\left(E_{k}\right)\right\rangle=1.9 \times 10^{13} \mathrm{~W}$. It may be noted that this value is important for magnetospheric processes but very small compared with the solar light radiation on the Earth's disk $\left(1.7 \times 10^{17} \mathrm{~W}\right)$.

The estimates of mean ion flux and mean dynamic pressure (momentum flux) on the geomagnetosphere are $\langle N\rangle=3.8 \times 10^{8} \mathrm{~cm}^{-2} \mathrm{~s}^{-1}$ and $\left\langle n m V^{2}\right\rangle=2.8 \times 10^{-8} \mathrm{dyne} / \mathrm{cm}^{2}$ (in good agreement with the Helios- $1 / 2$ estimate of $2.1 \times 10^{-8}$ dyne $/ \mathrm{cm}^{2}$ ).

The histograms of Fig. 1 and the data of Table 1 reveal noticeable differences between low-velocity and high-velocity solar wind streams. The mean kinetic energy flux in the high-velocity streams is more than twice that in the low-velocity streams. This divergence is even greater-by a factor of 3 to 4 -for the thermal energy flux. The distributions of the various quantities are similar, but somewhat longer "tails" are found for the high-velocity streams.

For the ion flux the dependency is reversed-the mean value in the low-velocity solar wind streams being about 1.6 times greater than in the high-velocity streams, i.e. the increase in density more than compensates the velocity decrease. The mean dynamic pressure in the solar wind high-velocity streams, however, is found to be slightly greater than in the low-velocity streams (by a factor 1.4) due to the extended tail distribution (see Fig. 1(e)). This implies that, on the average, the ion density falls off somewhat weaker 

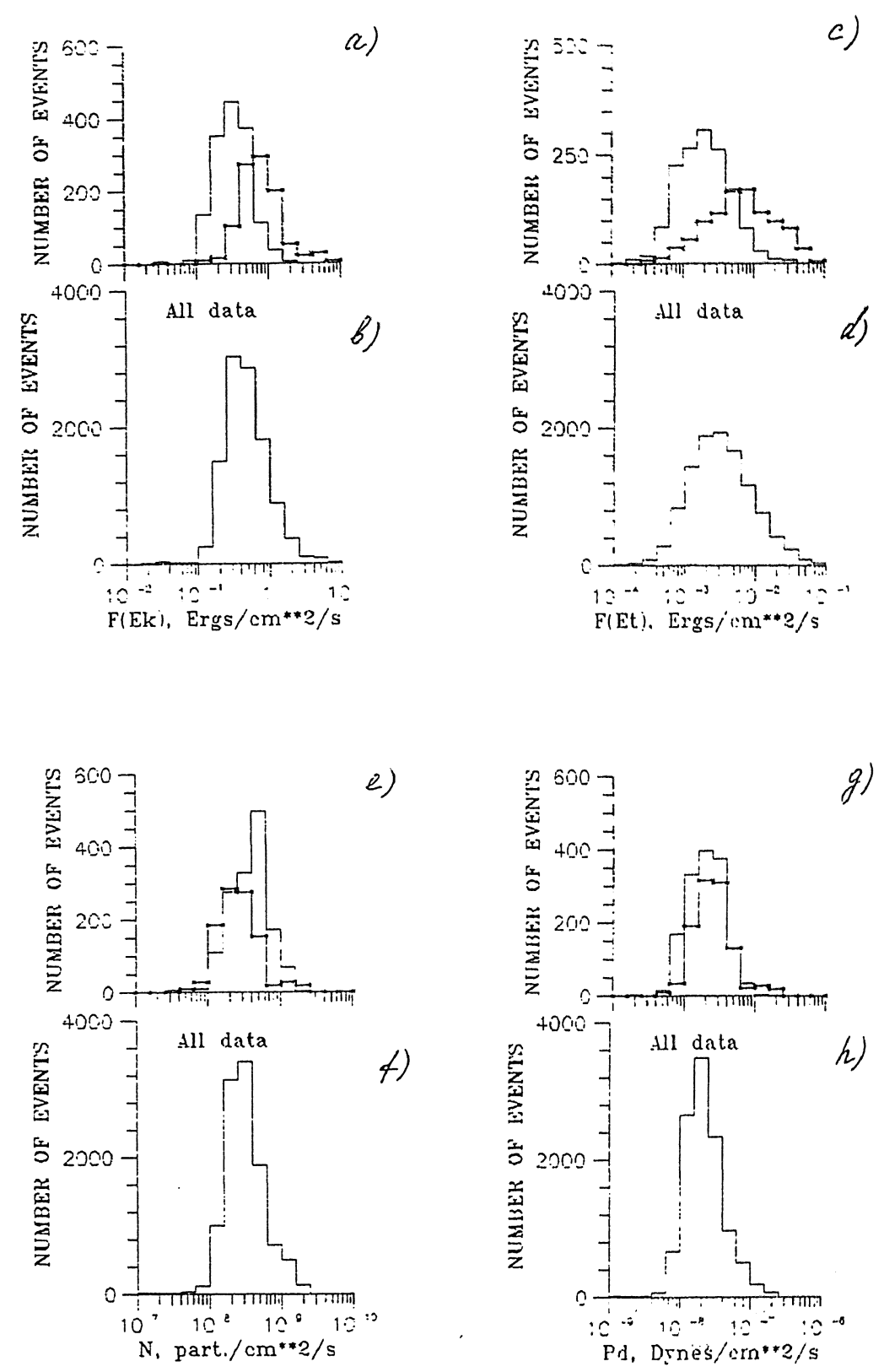

Fig. 1. Histograms of the kinetic energy flux $(a, b)$ thermal energy flux $(c, d)$, ion flux $(e, f)$ and dynamic pressure $(\mathrm{g}, \mathrm{h})$ values. Panels $\mathrm{b}, \mathrm{d}, \mathrm{f}, \mathrm{h}$-for all data (total cases $\sim 11000$ measurements); panels a, c, e, $\mathrm{g}$-for low-speed $(V<350 \mathrm{~km} / \mathrm{s})$ streams (thin lines, total cases $\sim 1500)$ and high-speed $(V>550 \mathrm{~km} / \mathrm{s}$ ) streams (lines with asterisks, total cases $\sim 1000$ ). 
Table 1. Mean values.

\begin{tabular}{|c|c|c|c|c|c|c|c|c|c|}
\hline \multirow[b]{2}{*}{ Quantity } & \multicolumn{3}{|c|}{$\begin{array}{l}\text { Vela, IMP } \\
(1971-74)\end{array}$} & \multicolumn{3}{|c|}{$\begin{array}{l}\text { Helios 1,2 } \\
(1975-76)\end{array}$} & \multicolumn{3}{|c|}{$\begin{array}{c}\text { Prognoz } 7 \\
(1978-79)\end{array}$} \\
\hline & $\begin{array}{l}\text { all } \\
\text { data }\end{array}$ & $\begin{array}{c}\text { slow } \\
\text { wind } \\
\left(\begin{array}{l}<350 \\
\mathrm{~km} / \mathrm{s}\end{array}\right)\end{array}$ & $\begin{array}{c}\text { fast } \\
\text { wind } \\
\left(\begin{array}{l}>650 \\
\mathrm{~km} / \mathrm{s}\end{array}\right)\end{array}$ & $\begin{array}{c}\text { all } \\
\text { data }\end{array}$ & $\begin{array}{c}\text { slow } \\
\text { wind } \\
\left(\begin{array}{l}<400 \\
\mathrm{~km} / \mathrm{s}\end{array}\right)\end{array}$ & $\begin{array}{c}\text { fast } \\
\text { wind } \\
\left(\begin{array}{l}>600 \\
\mathrm{~km} / \mathrm{s}\end{array}\right)\end{array}$ & $\begin{array}{l}\text { all } \\
\text { data }\end{array}$ & $\begin{array}{c}\text { slow } \\
\text { wind } \\
\left(\begin{array}{l}<350 \\
\mathrm{~km} / \mathrm{s}\end{array}\right)\end{array}$ & $\begin{array}{c}\text { fast } \\
\text { wind } \\
\left(\begin{array}{l}>550 \\
\mathrm{~km} / \mathrm{s}\end{array}\right)\end{array}$ \\
\hline $\begin{array}{l}\text { Kinetic } \\
\text { energy flux } \\
\mathrm{erg} / \mathrm{cm}^{2} / \mathrm{s} \\
(\sigma)\end{array}$ & $\begin{array}{l}0.70 \\
(0.5) \\
\end{array}$ & $\begin{array}{l}0.35 \\
(0.1) \\
\end{array}$ & $\begin{array}{l}1.1 \\
(0.2)\end{array}$ & 0.52 & 0.37 & 0.76 & $\begin{array}{l}0.63 \\
(.67)\end{array}$ & $\begin{array}{l}0.44 \\
(.19)\end{array}$ & $\begin{array}{l}1.0 \\
(.99)\end{array}$ \\
\hline $\begin{array}{l}\text { Thermal } \\
\text { energy flux } \\
\mathrm{erg} / \mathrm{cm}^{2} / \mathrm{s} \\
(\sigma)\end{array}$ & $\begin{array}{l}.016 \\
(.02)\end{array}$ & $\begin{array}{c}.004 \\
(.002)\end{array}$ & $\begin{array}{l}.023 \\
(.05)\end{array}$ & .016 & .011 & .023 & $\begin{array}{l}.007 \\
(.03)\end{array}$ & $\begin{array}{c}.003 \\
(.002)\end{array}$ & $\begin{array}{c}.012 \\
(.016)\end{array}$ \\
\hline $\begin{array}{c}\text { Ion } \\
\text { flux. } \times 10^{8} \\
\text { pt. } / \mathrm{cm}^{2} / \mathrm{s} \\
(\sigma)\end{array}$ & $\begin{array}{c}3.8 \\
(2.4)\end{array}$ & $\begin{array}{l}3.9 \\
(1.5)\end{array}$ & $\begin{array}{l}2.7 \\
(0.4)\end{array}$ & 2.9 & 3.7 & 2.0 & $\begin{array}{l}3.8 \\
(3.1)\end{array}$ & $\begin{array}{c}5.5 \\
(2.4)\end{array}$ & $\begin{array}{l}3.3 \\
(3.1)\end{array}$ \\
\hline $\begin{array}{c}\text { Dynamic } \\
\text { pres., } \times 10^{-8} \\
\text { dyne } / \mathrm{cm}^{2} \\
(\sigma)\end{array}$ & - & - & - & 2.1 & 2.1 & 2.3 & $\begin{array}{l}2.8 \\
(2.4)\end{array}$ & $\begin{array}{c}2.4 \\
(1.5)\end{array}$ & $\begin{array}{l}3.3 \\
(3.1)\end{array}$ \\
\hline
\end{tabular}

than $V^{-2}$ (NEUGEBAUER, 1976; YeRMOLAEV et al., 1989) as the solar wind velocity rises.

Comparing the energy and momentum fluxes for the two types of solar wind in question, it thus follows that the noticeable effects of the high-velocity streams on the geomagnetosphere may be associated with the solar wind's kinetic and thermal energy. On the other hand, additional compression of the magnetosphere, which is determined by the 6-th root of the dynamic pressure, should be insignificant ( $~ 5 \%)$.

\section{Variability of Energy and Momentum Flux}

To estimate the effects of solar wind energy and momentum flux variations on magnetospheric processes we should specify the applicable time and frequency ranges. For this discussion we take an one-hour interval as representative, because many geomagnetic indices are specified for a similar period. Here the ratio $\delta F /\langle F\rangle$ is taken as a natural measure of variability of the fluxes, where $\delta F$ is the standard deviation and $\langle F\rangle$ is the mean flux value in this hour interval.

The histograms of the distributions of variability (in this sense) of the kinetic and thermal energy, particle, and momentum fluxes are given in Fig. 2. We again divide the results into separate displays for all measurements (panels "b", "d", "f", "h") and for low-velocity and high-velocity solar wind streams (panels "a", "c", "e", "g"). The total amount of data is 1640 hours, for low speed -220 hours, for high speed-175 hours. Table 2 shows the mean variability for all parameters considered. The variability of the kinetic energy flux over a one-hour interval, averaged for all data, is rather low: $\left\langle\delta F\left(E_{k}\right) /\left\langle F\left(E_{k}\right)\right\rangle\right\rangle$ 

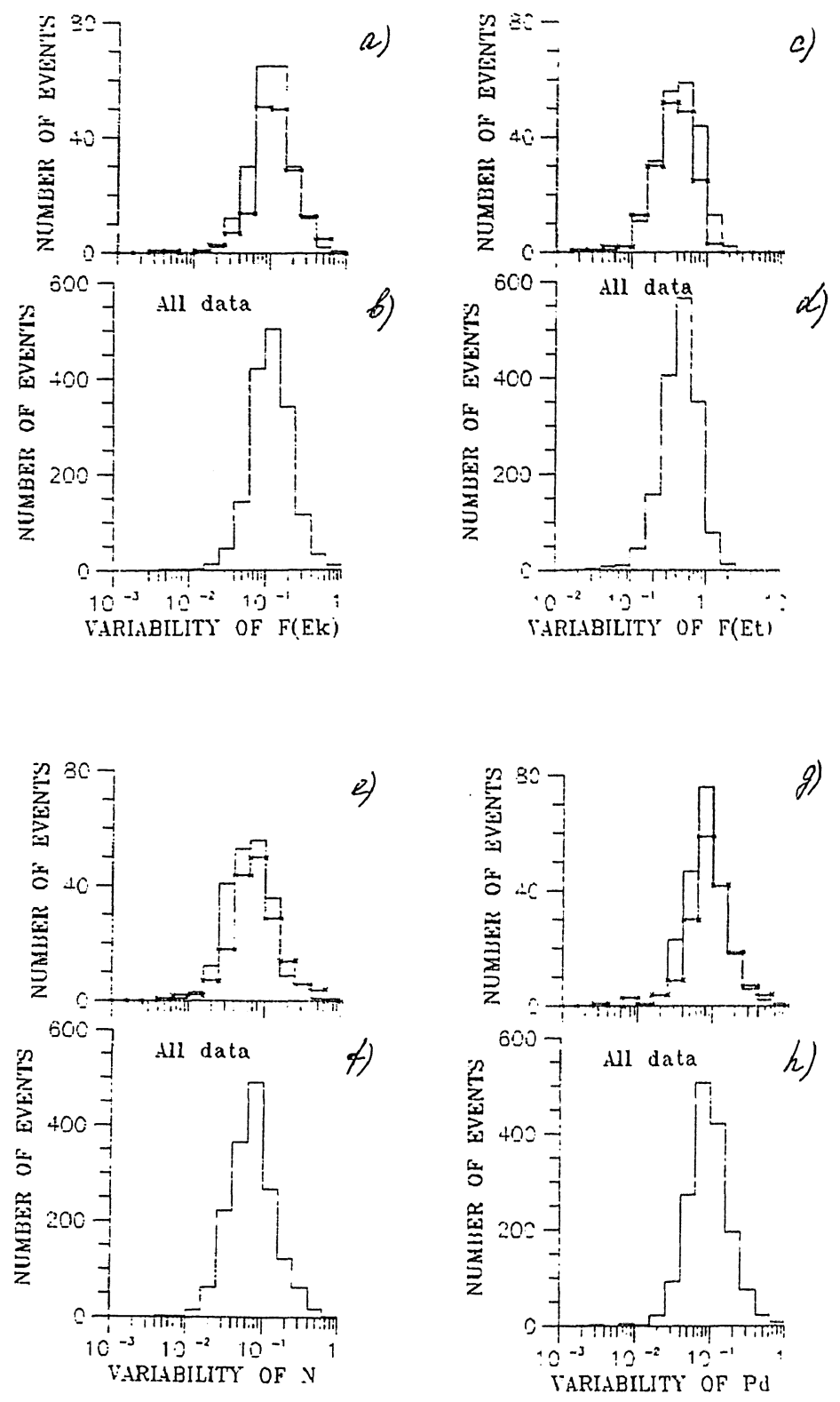

Fig. 2. Histograms of variability over one hour (see text) of the kinetic energy flux, thermal energy flux, ion flux and dynamic pressure. Ordering of panels-as in Fig. 1. Total cases-1640 hours all data, 220 hours-slow wind, 175 hours-fast wind.

$=0.14$. The histogram of Fig. 2(b) shows that $80 \%$ of the measurements have a variability in the $8-20 \%$ interval. The mean value of the particle flux variability is even less $\langle\delta N /\langle N\rangle\rangle=0.094$, but the histogram of this distribution (Fig. 2(f)) is somewhat wider: $65 \%$ measurements are in the $6-15 \%$ interval. As one might expect, the variability of the 
ion thermal energy is much higher: $\left\langle\delta F\left(E_{l}\right) /\left\langle F\left(E_{t}\right)\right\rangle\right\rangle=0.52$. This may be caused not only by temperature variations but also by low measurement accuracy. The solar wind dynamic pressure displays the weakest variability.

The data of Table 2 and Fig. 2 imply that the mean variability of energy and momentum fluxes for different types of solar wind is essentially the same over one-hour intervals, i.e. the high- and low-velocity streams are no different with respect to this definition of variability. One would thus expect that the effects on the geomagnetosphere associated with energy and momentum variations would be similar for both slow and fast solar wind, not only qualitatively, but quantitatively. A qualitative conclusion was drawn from IMP data (FELDMAN et al., 1977) that high-speed streams displayed less variability than the slow-speed ones. Since this inference referred to time-scales of several days or more, it is not in conflict with the Prognoz data on a 1 hour scale. Note also that identification of the "slow" solar wind with the "quiet", as opposed to "fast" associated with "disturbed", is generally not correct.

\section{Fluctuation Spectra of the Energy and Particle Fluxes}

The frequency dependence of the solar wind variability is usually described by power spectra of its basic parameters (velocity, density etc.). The phase relations between their variations (for example, anticorrelation of $V$ and $n$ over one hour time-scales) may lead to significant differences in the frequency dependence of energy and particle flux fluctuations from those of the basic parameters. We therefore determined the power spectra of the energy and particle flux fluctuations for several 2-3 days intervals of measurements. Figures 3 and 4 show examples of the spectra of fluctuations over the range $10^{-5}-10^{-3} \mathrm{~Hz}$ for low-velocity and high-velocity streams respectively.

Such power spectra have a steeply decreasing fluctuation intensity dependence on frequency, but also display some peculiar differences. The spectral power level of kinetic energy flux fluctuations in the lower frequency range $\left(2-5 \times 10^{-5} \mathrm{~Hz}\right)$ varies from $3 \times 10^{1}$ to $10^{4}\left(\mathrm{erg} / \mathrm{cm}^{2} \mathrm{~s}\right)^{2} / \mathrm{Hz}$ from event to event. For the ion flux the fluctuation intensity at lower

Table 2. Relative variations $\langle\delta X \mid\langle X\rangle\rangle$ by Prognoz 7 measurements.

\begin{tabular}{cccc}
\hline Quantity & $\begin{array}{c}\text { all } \\
\text { data }\end{array}$ & $\left.\begin{array}{c}\text { slow } \\
\text { wind } \\
(<350 \\
\mathrm{km} / \mathrm{s}\end{array}\right)$ & $\begin{array}{c}\text { fast } \\
\text { wind } \\
\left(\begin{array}{l}>550 \\
\mathrm{~km} / \mathrm{s}\end{array}\right)\end{array}$ \\
\hline $\begin{array}{c}\text { Kinetic } \\
\text { energy } \\
\text { flux }\end{array}$ & 0.14 & 0.12 & 0.13 \\
\hline $\begin{array}{c}\text { Thermal } \\
\text { energy } \\
\text { flux }\end{array}$ & 0.52 & 0.49 & 0.41 \\
\hline $\begin{array}{c}\text { Ion } \\
\text { flux }\end{array}$ & 0.094 & 0.081 & 0.094 \\
\hline $\begin{array}{c}\text { Dynamic } \\
\text { pressure }\end{array}$ & 0.11 & 0.09 & 0.10 \\
\hline
\end{tabular}




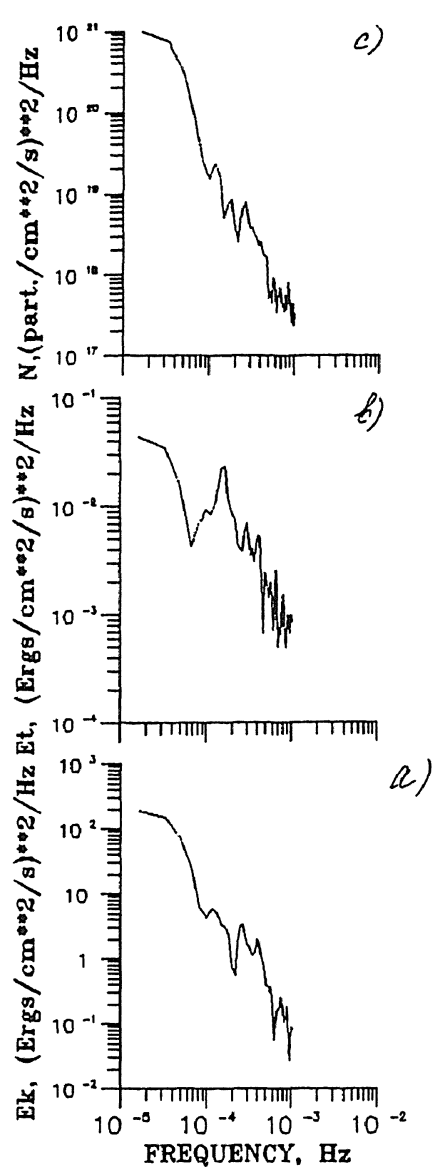

Fig. 3
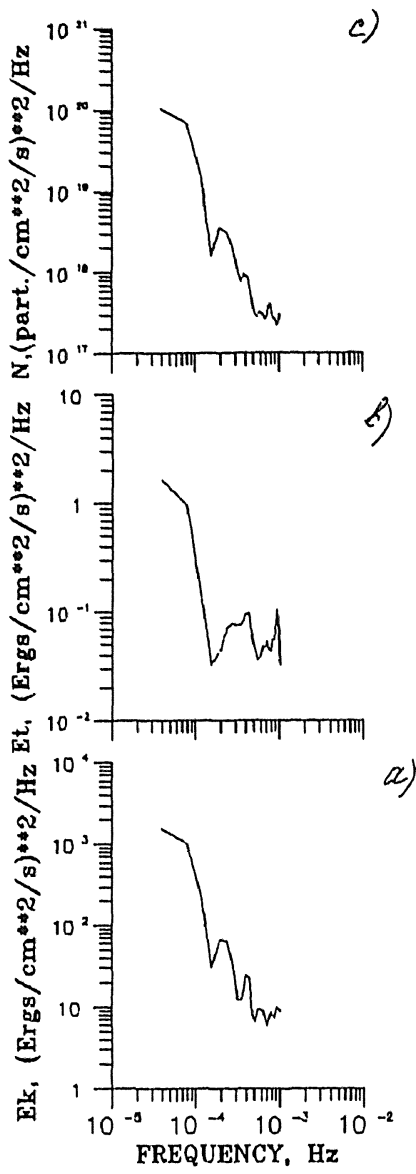

Fig. 4

Fig. 3. Power spectra of fluctuations of kinetic energy flux (a), thermal energy flux (b), ion flux (c) for the low-velocity stream on Dec. 1-4, 1978.

Fig. 4. Same as Fig. 3 for high-velocity stream on April, 29-30, 1979.

frequencies $\left(2-5 \times 10^{-5} \mathrm{~Hz} \text { ) varies from } 10^{-1} \text { to } 10^{3} \text { (part. } / \mathrm{cm}^{2} \mathrm{~s}\right)^{2} / \mathrm{Hz}$.

In most events the energy and particle flux fluctuation spectra can be well approximated by the power dependence $\left(F \sim f^{-\gamma}\right)$. In many observations (but not all) the spectra are subdivided into two frequency ranges:

- low frequencies $\left(10^{-5}\right.$ to $\left.1.5-4 \times 10^{-4} \mathrm{~Hz}\right)$ : steeply decreasing intensity;

- high frequencies $\left(1-3 \times 10^{-4}\right.$ to $\left.10^{-3} \mathrm{~Hz}\right)$ : more gradual fall off.

For these spectra the slopes of the low-frequency and high-frequency parts were separately estimated, just as done previously (LUTTREL and RICHTER, 1988) for the solar wind velocity.

Estimates of the fluctuation power spectrum slope $\gamma$, averaged individually for the low and high frequency spectral ranges for both slow and fast solar wind, are summarized in Table 3. Some evident trends revealed by this study are: 
Table 3. Slopes of the power spectra $(\gamma)$.

\begin{tabular}{ccccccc}
\hline \multirow{2}{*}{ Quantity } & \multicolumn{2}{c}{ slow wind } & & \multicolumn{2}{c}{ fast wind } \\
\cline { 2 - 3 } \cline { 6 - 6 } & l.f. & h.f. & & l.f. & h.f. \\
\hline $\begin{array}{c}\text { Kinetic } \\
\text { energy flux }\end{array}$ & 1.9 & 0.73 & & 4.0 & 1.0 \\
\hline $\begin{array}{c}\text { Ion } \\
\text { flux }\end{array}$ & 2.2 & 1.0 & & 5.2 & 1.4 \\
\hline
\end{tabular}

- the spectral slopes in the low-frequency part are much steeper (by a factor of 2-4) than in the high-frequency part;

- the slopes of the kinetic energy flux and particle flux power spectra differ insignificantly, but it is possible that the latter are higher by $20-50 \%$;

- the low-frequency spectral slopes for the low-velocity streams are appreciably weaker (about $1 / 2$ ) than those for the high-velocity streams.

The above given results refer to the energy and particle flux fluctuations in the range from several minutes to one day. As mentioned earlier, however, Prognoz-8, 10 sometimes measured the ion flux variability on time scales ranging down to fractions of seconds, i.e. a regime corresponding to the modes of many geomagnetic pulsations. Figure 5, constructed from the data of paper (CHASHEY et al., 1988), gives an example of the ion flux fluctuation power spectrum in the range $5 \times 10^{-3}-10 \mathrm{~Hz}$. This spectrum was obtained when a $400 \mathrm{~km} / \mathrm{s}$ velocity stream was observed near its interaction region with a highervelocity stream. This graph shows that the spectrum can be also well approximated by a power-low dependence. Here the power-low slope $\gamma \sim 1.5$ in the range $5 \times 10^{-3}-6 \times 10^{-1} \mathrm{~Hz}$, i.e. close to the results we obtained for the range $10^{-4}-10^{-3} \mathrm{~Hz}$. As frequency increases, the spectrum becomes steeper and the slope reaches $\sim 2.3$.

One more feature of the spectra shown in Figs. 3 and 4 should be mentioned, viz., that some spectra show a maximum at frequences from $9 \times 10^{-5}$ to $3 \times 10^{-4} \mathrm{~Hz}$. This

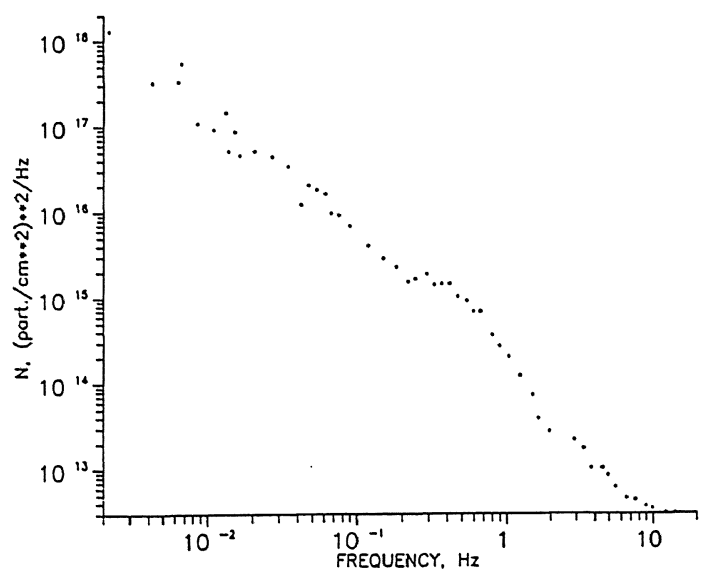

Fig. 5. Power spectrum of ion flux high-frequency fluctuations. 
maximum might reflect the remnants of supergranular structure on the Sun's surface (THIEME et al., 1989), which, however, in many cases may be masked by the Alfven oscillations of the ion velocity.

5. Discontinuities in Solar Wind Energy and Momentum Fluxes Due to an Interplanetary Shock Wave

Among the strongest and probably most geoeffective energy flux and solar wind momentum variations are those associated with interplanetary shock waves. Specifically, for the majority of such waves recorded by Prognoz-7, 8 (ZASTENKER and BORODKOVA, 1984), the jumps in the hydrodynamic parameters at the shock front and the time variations of theses parameters behind the front were measured. These data were also used to calculate the energy and momentum flux variations.

Figures 6 and 7 give two examples of rather typical events-interplanetary shock

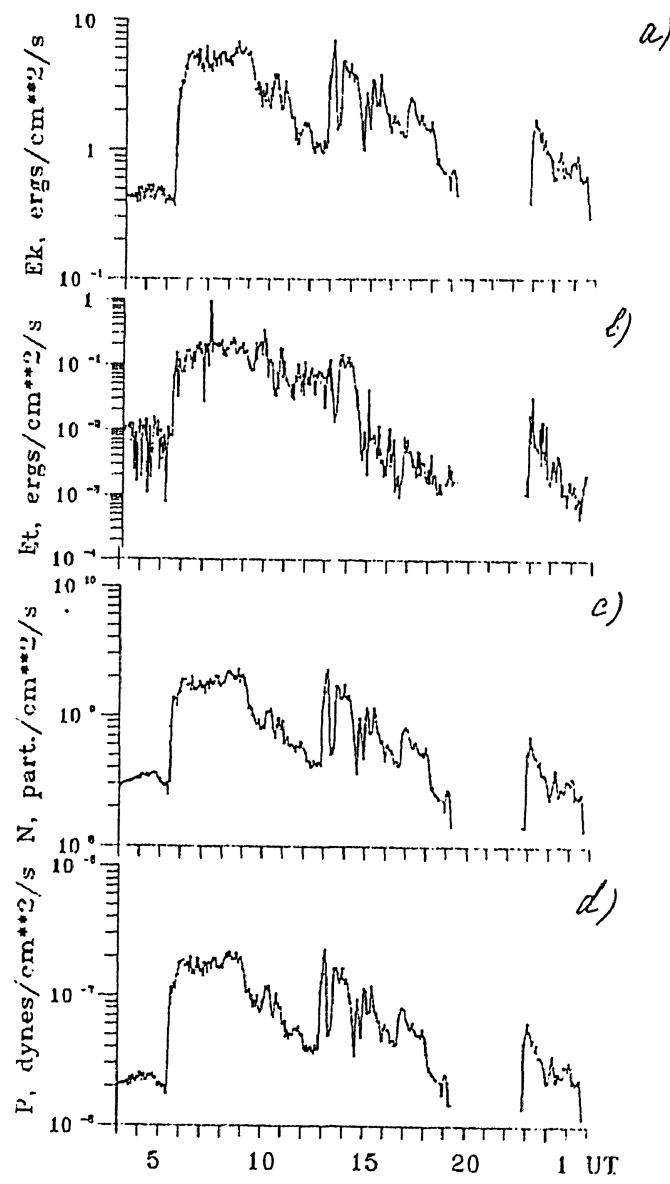

INTERPLANETARY SHOCK WAVE, MARCII, 5-6, 1981.

Fig. 6. Time variation of the kinetic energy flux (a), thermal energy flux (b), ion flux (c) and dynamic pressure

(d) for the interplanetary shock wave on March 5/6, 1981. 


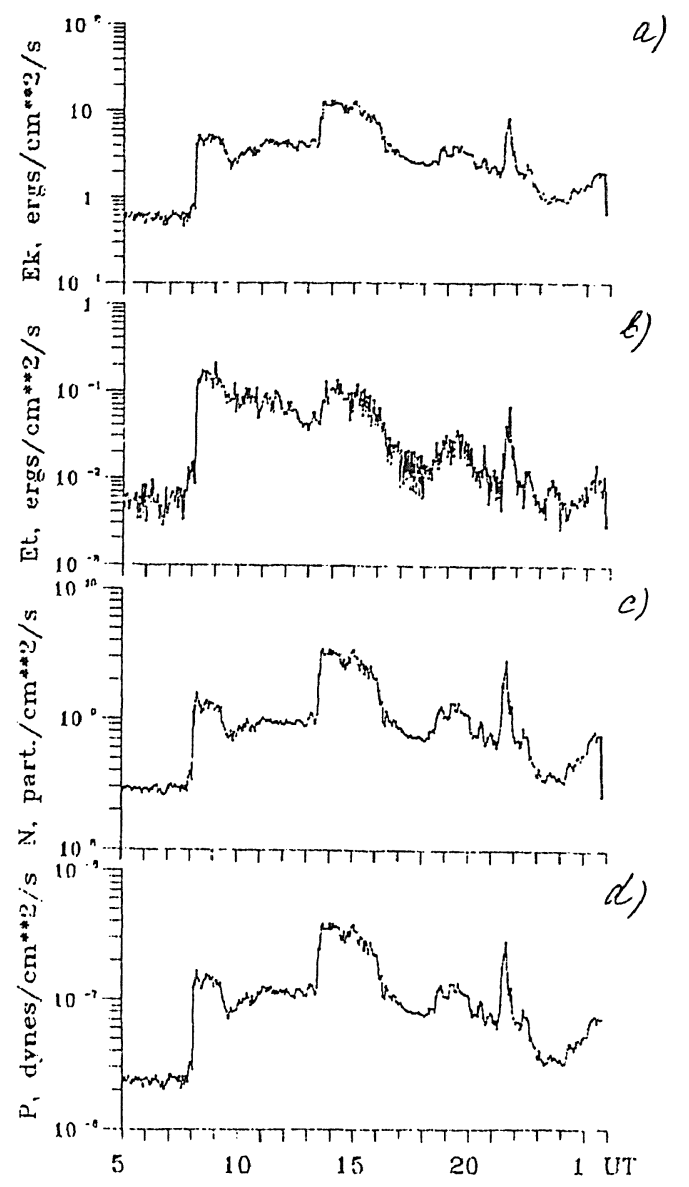

INTERPLINETAPY SHOCK WAYF, APRIL, 26-27, 1981.

Fig. 7. Same as Fig 6 for the interplanetary shock wave on April 26/27, 1981.

waves that arrived at Earth on March 5/6 and Aprin 26/27, 1981. A large discontinuous jump in the parameters considered here is a general feature of such events. The kinetic energy flux, for example, increases from a value close to the mean $\left(\sim 0.5-0.6 \mathrm{erg} / \mathrm{cm}^{2} \mathrm{~s}\right)$ before the shock wave to $\sim 6 \mathrm{erg} / \mathrm{cm}^{2}$ s for March $5 / 6$ and even to $\sim 12 \mathrm{erg} / \mathrm{cm}^{2}$ s for April $26 / 27$, i.e. more than an order of magnitude. The thermal energy flux and the ion flux also increase by more than a factor of ten (to $\sim 0.2 \mathrm{erg} / \mathrm{cm}^{2} \mathrm{~s}$ and to $\sim 2-3 \times 10^{9}$ part. $/ \mathrm{cm}^{2} \mathrm{~s}$, respectively).

The jump in dynamic pressure is $1-2 \times 10^{-7}$ dynes $/ \mathrm{cm}^{2}$. According to numerical simulations of such shocks (SMITH and DRYER, 1988), these values provide an estimate of the original energy input to the shock wave of about $1-3 \times 10^{31}$ ergs. The two events shown here are noticeably different in their duration. In the March 5/6 event the kinetic energy flux falls to a level close to the normal about 6 hours after the disturbance begins, although some flux bursts are observed in the next 6 hours. In the second case the energy flux considerably exceeds the mean level for more than 16 hours. During this interval the 
power level of the various flux variations in the range $10^{-5}-10^{-3} \mathrm{~Hz}$ remains high, close to or higher than the highest fluctuation level observed in other high-velocity solar wind streams, and by one to one and a half orders of magnitude higher than that prior to the shock wave arrival.

Due to space limitations we are unable to consider all consequences of such strong increases in the solar wind energy and momentum flux (magnetospheric compression, strong geomagnetic disturbances, etc.), some of which (for example the events of August 1972) can be quite extreme.

\section{REFERENCES}

Avanov, L., N. Borodkova, Z. Nemecek, A. Omeltchenko, J. Safrankova, A. Skalski, Yu. Yermol.aev, and G. Zastenker, Some features of solar wind protons, $\alpha$-particles and heavy ions behaviour: the Prognoz 7 and Prognoz 8 experimental results, Czechoslovak. J. Phisics, B37, 759, 1987.

BiermanN, L., Kometenschweife und solare Korpuskularstralung, Z. Astrophys., 29, 276, 1951.

Chashey, I. V. et al., Power spectra of the interplanetary plasma density fluctuations by Prognoz 8 measurements, Kosmich. Issled., 26, N2, 289, 1988 (in Russian).

Feldman, W. C., J. R. Asbridge, S. J. Bame, and J. T. Gosling, Interplanetary plasma, in The Solar Output and Its Variations, edited by O. R. White, p. 255, Colorado Univ. Press, Boulder Col., 1977.

Hundhausen, A. J., Coronal Expansion and Solar Wind, Springer, Berlin, 1972.

LUTTREL, A. and A. RichTER, The role of Alfvenic fluctuations in MHD turbulence evolution between 0.3 and $1.0 \mathrm{AU}$, in Solar Wind 6, edited by V. J. Pizzo et al., p. 335, HAO/NCAR Techn. Note, v. 1, 1988.

Neugebauer, M., The quiet solar wind, J. Geophys. Res., 81, 4664, 1976.

PARKer, E. N., Dynamics of the interplanetary gas and magnetic fields, Astrophys. J., 128, 664, 1958.

SCHWENN, R., The "average" solar wind in the inner heliosphere: structures and slow variations, in Solar Wind 5, edited by M. Neugebauer, p. 489, NASA Conf. Publ. 2280, 1983.

SMITH, Z. and M. DRYER, A study of the temporal and spatial evolution of shocks within I AU, in Solar Wind 6, edited by V. J. Pizzo et al., p. 309, HAO/NCAR Techn. Note, v. 1, 1988.

Thieme et al., Are structures in high-speed streams signatures of coronal fine structures?, Adv. Space Res., 9, N4, 127, 1989.

VAISBERG, O. L. et al., Interplanetary and magnetospheric plasma diagnostic experiment onboard Venera 11 , 12 and Prognoz 7, Kosmich, Issled., 17, N5, 780, 1979 (in Russian).

Yermolaev, Yu. I., V. V. Stupin, G. N. Zastenker, G. P. Khamitov, and I. Koz.Ak, Variations of solar wind proton and alpha-particle hydrodynamic parameters: Prognoz 7 observations, Adv. Space Res., 9, N4, $123,1989$.

Zastenker, G. N. and N. L. Borodkova, Some features of the interplanetary disturbances in the post-solar maximum year period, Adv. Space Res., 4, N7, 347, 1984.

Zastenker, G. N. et al., Solar wind observation with high-time resolution, Kosmich. Issled., 20, N6, 900,1982 (in Russian).

Zastenker, G. N., Yu. I. Yermolaev, V. I. Zhuravlev, N. L. Borodkova, Z. Nemecek, and J. SAFrAnkova, Large and middle-scale phenomena in the interplanetary medium: Prognoz 7,8,10 observations, $A d \nu$. Space Res., 9, N4, 117, 1989. 